\title{
O ENSINO MÉDIO E O EXERCÍCIO PROFISSIONAL NO CONTEXTO DA ENFERMAGEM BRASILEIRA*
}

\author{
Rosana Aparecida Spadoti Dantas** \\ Olga Maimoni Aguillar***
}

DANTAS, R.A.S.; AGUILLAR, O.M. O ensino médio e o exercício profissional no contexto da enfermagem brasileira.

Rev.latino-am.enfermagem, Ribeirão Preto, v. 7, n. 2, p. 25-32, abril 1999.

A formação profissional na área de enfermagem brasileira tem sido motivo de preocupação ao longo da história da enfermagem moderna, em nosso país. No contexto histórico em que a enfermagem brasileira se desenvolveu, buscamos analisar a evolução da legislação norteadora da formação dos seus profissionais de nível médio, bem como as leis que regem a prática destes trabalhadores.

UNITERMOS: enfermagem-ensino, legislação de enfermagem

\section{APRESENTAÇÃO}

A formação profissional na área tem sido motivo de preocupação ao longo da história da enfermagem brasileira e não se dissocia de uma questão mais abrangente que é a formação profissional na área da saúde como um todo. Tal preocupação tem se evidenciado nos pronunciamentos de representantes dos órgãos de classe, em eventos e em publicações. Observa-se que, também, no âmbito dos órgãos formadores, esta inquietação tem sido objeto de análise, de docentes e discentes, dos cursos de graduação e pós-graduação. Desta forma, o presente trabalho originou-se de discussões no transcorrer de disciplina de pós-graduação, quando foi evidenciada a lacuna existente nas publicações referentes à temática: ensino médio.

O trabalho na área da saúde, independente do conceito de saúde e do estágio de desenvolvimento de cada modalidade de sociedade, exige determinados prérequisitos. No mundo todo, a aquisição destes requisitos que credenciam o indivíduo para o trabalho nesta área, depende de um processo formalmente atrelado e embutido na escolarização do mesmo (CHRISTÓFARO, 1994).

A legislação educacional no Brasil prevê e estabelece normas e critérios que norteiam tanto a educação geral quanto a formação profissional. A formação profissional, na área da saúde, é definida pelo sistema educacional, como sendo de primeiro e segundo graus (habilitações profissionais) e, também, no ensino superior (profissões universitárias). Segundo CHRISTÓFARO (1994), “a expectativa em relação a esta formação é que atenda e responda à complexa e dinâmica divisão técnica que marca o trabalho em saúde, assim como prepare diferentes profissionais que, individualmente e no seu conjunto, acompanhem e incorporem as mudanças advindas do desenvolvimento técnico-científico, na perspectiva de intervirem positivamente, nas necessidades de saúde de cada pessoa e da população".

A assistência de enfermagem, no Brasil, tem sido feita em grande parte, por um contingente de pessoas sem preparo formal para o trabalho. Tal situação, determinada social e historicamente, tem em vista a lógica do modo de produção capitalista e traz distorções na prática de enfermagem e na produção dos serviços de saúde. Estes serviços têm se mostrado ineficazes, dispendiosos, pouco produtivos e até mesmo iatrogênicos (BRANDT \& MAGALHÃES, 1992).

A prática do sistema de saúde, público e privado, de absorver pessoal sem qualificação específica e inserilo nas mais diferentes unidades de trabalho, não é recente. O desconhecimento do número total desses trabalhadores, em todas as áreas, demonstra a incapacidade de conhecer as conseqüências e o impacto da sua participação na

\footnotetext{
* Trabalho realizado para conclusão da disciplina "Análise crítica da evolução da assistência de enfermagem”, do Programa Interunidades de Doutoramento da Escola de Enfermagem de Ribeirão Preto da Universidade de São Paulo

** Aluna do Programa Interunidades de Doutoramento da Escola de Enfermagem de Ribeirão Preto da Universidade de São Paulo *** Professora Doutora do Departamento de Enfermagem Geral e Especializada da Escola de Enfermagem de Ribeirão Preto da Universidade de São Paulo
} 
organização do processo e na qualidade do produto do trabalho em saúde. Estima-se que, somente no estado de São Paulo, no que se refere à enfermagem, existam cerca de oitenta mil trabalhadores sem qualificação específica (ABEn, 1997).

Nossa vivência no curso de licenciatura, têm-nos mostrado, também, a dificuldade de acesso e compreensão por parte dos alunos, do conjunto de atos legais que têm regulamentado a formação e o exercício do profissional de nível médio em enfermagem. Este trabalho, portanto, tem como objetivo sistematizar, cronologicamente, os atos legais relacionados ao ensino e à atuação deste profissional, a partir da década de 40, quando se deu início o seu processo de regulamentação (BRASIL, 1974a).

\section{A LEGISLAÇÃO E O CONTEXTO HISTÓRICO}

O início do século XX, no Brasil, foi marcado pelas péssimas condições de vida da população e por epidemias que assolavam as cidades, principalmente as portuárias, o que acarretou em um movimento voltado para o saneamento e a saúde pública e o surgimento de outros profissionais, além do médico. Tal movimento culminou com a criação do Departamento Nacional de Saúde Pública, os serviços de enfermagem de Saúde Pública e a Escola de Enfermagem Anna Nery (BAPTISTA \& BARREIRA, 1997).

Na história da educação brasileira, ao que se refere às várias reformas sofridas, observa-se que as mudanças se deram de forma mais acentuada a partir de 1930. A urbanização e a conseqüente demanda escolar, assim como a industrialização, modificaram o quadro educacional brasileiro nesta época. Na década de 30, o Decreto $n^{0}$ 20109/31 (BRASIL, 1974a) regulamentou a prática da enfermagem no Brasil e fixou condições para a equiparação das escolas de enfermagem à Escola Anna Nery, a qual foi estabelecida como escola oficial padrão para o ensino da enfermagem. No entanto, o referido decreto não trouxe referências ao profissional de nível médio (OLIVEIRA, 1979; ABEn, 1985; BAPTISTA \& BARREIRA, 1997).

Nos anos 40, o quadro social urbano passou a se diferenciar através da consolidação de uma sociedade industrial. Os trabalhadores assalariados passaram a exercer pressões para garantir a interferência estatal na conquista dos direitos sociais, as quais tiveram grande ênfase na área, da saúde, favorecendo a expansão e ampliação de seus serviços.

Como resultado desta situação houve a condução da prática institucionalizada de atenção ao doente, levando à necessidade de formação específica de pessoal para o exercício da enfermagem. Surgiram os hospitais escolas para servir de campo de prática dos alunos de medicina, o que possibilitou a aprendizagem de outras categorias da saúde. Tais hospitais incorporaram modernas tecnologias no tratamento ao doente, tomando características de uma organização complexa, necessitando de número maior de pessoal auxiliar, treinado para o cuidado direto, uma vez que as enfermeiras eram solicitadas para as atividades administrativas. Foi, então, estimulada a criação de cursos de auxiliares de enfermagem e a organização de programas de treinamento em serviço (OLIVEIRA, 1979; ABEn, 1985).

Em 1942, ocorreu a reorganização da Escola Profissional de Enfermeiros que passou a se chamar Escola de Enfermeiros Alfredo Pinto, a qual tinha por finalidade preparar enfermeiros auxiliares para os serviços sanitários e assistenciais. O Decreto-Lei $\mathrm{n}^{\circ}$ 10472/42 (BRASIL, 1974a), aprovou a regulamentação desta escola e estabeleceu que o curso de enfermeiros auxiliares deveria ser feito em seis períodos, com a duração total de 18 meses. As disciplinas a serem ministradas eram aquelas necessárias ao exercício da profissão e enfocavam o aprendizado das técnicas de enfermagem.

A habilitação e a fiscalização do exercício profissional para os práticos de enfermagem, em 1945, passou a pertencer ao Serviço Nacional de Fiscalização da Medicina (Decreto-Lei $n^{\circ}$ 83445). No ano seguinte, ocorreu a regulamentação dos exames de habilitação para os práticos de enfermagem e parteiras práticas; e, aqueles que tivessem mais de dois anos de efetivo exercício profissional, em estabelecimentos hospitalares, poderiam submeter-se aos referidos exames para obtenção do certificado de "prático de enfermagem" e "parteira prática", respectivamente (Decreto-Lei no 8778/46) (BRASIL, 1974a).

Após 1946, ocorreu processo de redemocratização no país, que se seguiu à Segunda Guerra Mundial. O Brasil ganhou uma nova Constituição e coube à União legislar sobre as diretrizes e bases da educação nacional, contrapondo-se a Constituição anterior, de 1937, que fazia concessões à iniciativa privada, quanto à liberdade de ensino (BAPTISTA \& BARREIRA, 1997).

Em 1949, as escolas de enfermagem passaram a ser reguladas pelo então Ministério da Educação e Saúde, que através da Lei $n^{\circ} 775$ (BRASIL, 1974a), dispôs sobre o ensino de enfermagem no país e estabeleceu que este deveria estar compreendido em dois cursos ordinários: o de enfermagem e o de auxiliar de enfermagem.

O Decreto $n^{\circ} 27426 / 49$, que regulamentou a referida Lei, aprovou as bases para os dois cursos de enfermagem. Estabeleceu que o curso de auxiliar tinha por objetivo o adestramento de pessoal capaz de auxiliar 
o enfermeiro em suas atividades de assistência curativa; o conteúdo a ser ministrado (introdução; noções de ética; corpo humano e seu funcionamento; higiene em relação à saúde; economia hospitalar; alimento e seu preparo e enfermagem fundamental) e dispunha sobre a obrigatoriedade dos alunos realizarem estágios em hospitais gerais, e fazerem rodízios nas enfermarias de clínica médica, clínica cirúrgica, sala de operações e central de material, berçário e cozinha geral.

O curso era de 18 meses, sendo o aluno obrigado a cumprir 44 horas de atividades escolares semanais, incluindo os estágios. Esta carga horária trazia embutido, o aproveitamento destes alunos como mão de obra dos hospitais recém instalados. Ficou estabelecido que o ensino de enfermagem auxiliar só podia ser ministrado por enfermeiros.

$\mathrm{Na}$ década de 50 , com a ampliação do parque industrial e o crescimento da população urbana e previdenciária, a saúde pública, perdeu ainda mais sua importância nas políticas de saúde e se fortaleceu a atenção médica individualizada (OLIVEIRA, 1979; ABEn, 1985). O processo de industrialização acelerada que o Brasil viveu a partir desta década, gerou uma massa operária que deveria ser atendida por um sistema de saúde voltado, não mais para o saneamento do espaço de circulação de mercadorias, mas para o corpo do trabalhador, visando manter e restaurar a sua capacidade produtiva (MENDES, 1994). Ocorreu, então, a proliferação da rede hospitalar, abrindo um novo espaço para a atuação da enfermagem, ao mesmo tempo que havia a necessidade de maior número de trabalhadores com preparo específico para o exercício da profissão.

$\mathrm{Na}$ análise de CARVALHO (1976) e ALMEIDA \& ROCHA (1986) a criação e a regulamentação de cursos regulares de auxiliares de enfermagem, para o preparo de grande número de pessoal, para a assistência direta aos pacientes internados, foi a solução encontrada, na época, para resolver uma situação emergente devido à deficiência numérica de enfermeiros e do preparo dispendioso e demorado destes profissionais.

Foi possível ampliar as possibilidades de formação de profissionais de enfermagem de nível médio, com a promulgação da Lei $n^{\circ} 2367 / 54$, a qual dispunha sobre o ensino de enfermagem em cursos volantes. Tais cursos poderiam ser realizados em localidades onde não existissem escolas de enfermagem, mas que dispusessem de hospitais com possibilidades reais para a formação de auxiliares. Os cursos também deveriam obedecer às disposições legais anteriores (BRASIL, 1974a).

Devido ao crescimento do pessoal de enfermagem nos serviços de saúde, verificou-se a necessidade de disciplinar o exercício profissional, o que ocorreu através da Lei $n^{0}$ 2604/55 (BRASIL, 1974a), posteriormente regulamentada pelo Decreto $\mathrm{n}^{\circ} 50387 / 61$
(BRASIL, 1974b). Apesar da nova legislação norteadora, a fiscalização do exercício profissional da enfermagem, em suas várias categorias, continuou a pertencer ao Serviço Nacional de Fiscalização da Medicina, tendo em vista a ausência de órgãos de classe com tal competência legal. Tal possibilidade só ocorreu com a criação dos Conselhos Federal e Regionais de Enfermagem, com a promulgação da Lei no 5905/73 (ABEn, 1987).

A Lei $n^{\circ} 2604 / 55$, estabeleceu que poderiam exercer a enfermagem no país, no que se refere aos profissionais de nível médio, os auxiliares de enfermagem e os práticos de enfermagem ou enfermeiros práticos, desde que sob a supervisão de enfermeiros ou médicos. As atribuições para estes profissionais eram todas as atividades da profissão, excluídas as de competência exclusiva dos enfermeiros (direção de serviços de enfermagem nos estabelecimentos hospitalares e de saúde pública; participação do ensino e direção de escolas de enfermagem e de auxiliares de enfermagem; participação em bancas examinadoras de práticos de enfermagem). Tal legislação não correspondia à realidade daquele momento, devido à carência de enfermeiros e às necessidades de mão de obra de enfermagem (ALCÂNTARA, 1966).

Paralelamente à promulgação destes atos legais, continuou a existir na prática de enfermagem, o ingresso de trabalhadores não qualificados, sem ensino formal, os quais recebiam, geralmente, treinamento em serviços por parte de médicos e enfermeiros, quando estes estavam presentes. Em 1958, a ABEn publicou o "Levantamento dos Recursos e Necessidades de Enfermagem no Brasil", mostrando que a composição da força de trabalho em enfermagem, nos anos de 1956 e 1957, era de 4831 enfermeiros, 1982 auxiliares e 36118 atendentes (ABEn, 1980).

O Decreto 50387/61, acresceu às atribuições anteriores de enfermeiros e auxiliares a execução de atos que visassem: a educação sanitária do doente, da gestante ou do acidentado, bem como a educação sanitária do indivíduo, da família e de outros grupos sociais para a conservação e recuperação da saúde e prevenção de doenças. Mais tarde, durante o I Seminário Regional de Ensino Médio em Enfermagem, CARVALHO (1966) ponderou que o currículo dos auxiliares de enfermagem não contemplava os aspectos necessários às ações preventivas de educação sanitária, conforme fora atribuído pelo decreto acima.

O ano de 1961 também foi um ano importante na área de formação dos profissionais de enfermagem, com a promulgação da Lei ${ }^{\circ} 4024$, na qual foram fixadas as novas diretrizes e bases para a educação nacional (BRASIL, 1974b). A nova lei determinou a necessidade de serem alteradas as estruturas dos cursos de enfermagem. Além da obrigatoriedade de se fazer as duas 
séries do curso de auxiliar de enfermagem corresponderem aos dois primeiros anos ginasiais, com a inclusão de cinco disciplinas obrigatórias em seu currículo, deixou ainda a possibilidade para a criação de outro tipo de curso, o de técnico de enfermagem. Tal curso seria intermediário entre o de graduação e o de auxiliar e estaria na faixa do segundo grau, correspondendo ao curso colegial.

Apesar dessa lei ter aberto novas perspectivas para a educação da enfermagem, não foi possível um avanço imediato do ensino na área, devido às condições sócio-econômicas e culturais de muitas das regiões brasileiras e da carência de pessoal.

Mais tarde, a Portaria $\mathrm{n}^{\circ} 106 / 65$, do Ministério da Educação e Cultura, fixou normas para o currículo mínimo do Curso de Auxiliar de Enfermagem, estipulando a duração de dois anos letivos de 180 dias e a idade mínima de 16 anos para o ingressante. Além das cinco disciplinas gerais, relativas às duas primeiras séries ginasiais, as disciplinas específicas passaram a ser: fundamentos de enfermagem (anatomia, fisiologia e patologia); técnicas de enfermagem (médico-cirúrgica, materno-infantil e de saúde pública); higiene e profilaxia; e, ética e história de enfermagem. Novos locais de estágios foram acrescentados em clínica ginecológica e obstétrica; clínica urológica e clínica pediátrica (BRASIL, 1974b).

Outro aspecto a ser lembrado é que, a partir da década de 60 , ocorreu um processo de intensa medicalização da sociedade, com a ampliação do consumo de bens e serviços em saúde, resultado do avanço do complexo médico-industrial incentivado pela política sócio-econômica adotada no país. Há uma especialização do conhecimento médico e de enfermagem e a criação de unidades hospitalares cada vez mais complexas solicitando o emprego de profissionais da saúde nestas novas áreas.

A orientação do currículo das escolas de enfermagem continuou sendo, predominantemente, hospitalar, havendo uma concordância entre a formação profissional e a tendência do Estado em conferir prioridades ao tratamento curativo (OLIVEIRA, 1979; ABEn, 1985).

Os cursos de auxiliares de enfermagem progrediram rapidamente no Brasil. Segundo CARVALHO (1966), alguns cursos iniciaram suas atividades antes mesmo da promulgação da Lei 775/49, sendo que, de 1941 a 1947, funcionou apenas uma escola; em 1951, existiam doze escolas em funcionamento; num período de 10 anos, entre 1951 e 1961, foram criados 49 novos cursos e, em 1966, já totalizavam 76 escolas de auxiliares de enfermagem.

Houve no final da década de 60 e início dos anos 70 , incentivos para a criação de cursos técnicos em várias áreas da economia nacional, o que, no nosso entendimento, foi ao encontro dos interesses difundidos pela política adotada durante os anos do "milagre econômico", com a inserção do país na divisão internacional do trabalho e a necessidade de desenvolvimento acelerado. $\mathrm{Na}$ enfermagem, foram criadas quatro escolas técnicas de enfermagem, em caráter experimental (SEMINÁRIO REGIONAL DE ENSINO MÉDIO EM ENFERMAGEM, 1966).

Assim, no contexto do desenvolvimento sócioeconômico das décadas de 60 e 70 , a enfermagem se desenvolveu sob a influência da reforma do ensino médio e da reforma universitária, as quais propiciaram a revisão do currículo mínimo dos cursos, paralelamente à expansão dos cursos técnicos de enfermagem e a fixação dos currículos de enfermagem de primeiro e segundo graus (ABEn, 1985; OLIVEIRA, 1979).

Neste período, 1968, ocorreu a determinação da necessidade de formação pedagógica dos enfermeiros, através de cursos de licenciatura, como pré requisito para a docência no ensino médio (SECAF, 1987).

A Lei $n^{\circ} 5.692 / 71$ (BRASIL, 1974c) fixou as diretrizes e bases para o ensino de primeiro e segundo graus, possibilitando a reforma do ensino secundário. Estabeleceu como objetivo geral proporcionar ao educando a formação necessária ao desenvolvimento de suas potencialidades, como elemento de auto realização, qualificação para o trabalho e preparo para o exercício constante da cidadania. Ao dispor sobre o ensino supletivo, estabeleceu como finalidade do mesmo suprir a escolarização regular de adolescentes e adultos, proporcionando estudos de aperfeiçoamento ou atualização para aqueles que tinham seguido o ensino regular no todo ou em parte. No ano seguinte, o Parecer $n^{\circ} 45$ da Câmara de Ensino de $1^{\circ}$ e $2^{\circ}$ graus estabeleceu os mínimos a serem exigidos em cada habilitação profissional ou conjunto de habilitações afins no ensino de $1^{\circ}$ e $2^{\circ}$ graus (BRASIL, 1974c).

Em um país com um elevado grau de analfabetismo, a suplência foi, e continua sendo, uma solução educacional e formadora, ainda que paliativa. As dificuldades encontradas pelo pessoal sem formação específica na área, acarretou um novo pedido, encaminhado ao Presidente da República, pela Associação Brasileira de Enfermeiros e Massagistas Práticos, reivindicando o restabelecimento do Decretolei ${ }^{\circ} 8778 / 46$. Este decreto já havia sido restaurado em 1959, pela Lei ${ }^{0} 3.640$, estendendo os seus efeitos até 1964, permitindo aos práticos de enfermagem e parteiras em exercício, sem formação regular, a obtenção do certificado de "práticos", mediante a prestação de exames de habilitação. Aqueles que tivessem mais de 20 anos de efetivo exercício profissional estavam dispensados dos exames. A solicitação foi atendida pelo Conselho Federal de Educação através do Parecer n ${ }^{\circ}$ 934/72 (BRASIL, 1974c).

O Parecer n ${ }^{\circ} 3814 / 76$, do Conselho Federal de 
Educação, fixou os conteúdos curriculares mínimos, em termos da formação do auxiliar de enfermagem e revisou os estabelecidos pelo Parecer $45 / 72$, em relação ao técnico. As Resoluções n ${ }^{\circ} 7$ e n ${ }^{\circ} 8$, do Conselho Federal de Educação, em 1977, regulamentaram a formação de Técnicos e Auxiliares de Enfermagem. A Resolução $n^{0} 7$ instituiu os dois cursos como habilitações referentes ao $2^{\circ}$ grau e a Resolução $\mathrm{n}^{\circ} 8$ permitiu que o auxiliar de enfermagem fosse preparado ao nível de $1^{\circ}$ grau, intensivamente, em caráter emergencial, dada a realidade vivida pela clientela (GALVÃO, 1994).

O curso técnico de enfermagem foi denominado de habilitação plena e integralizado em 2760 horas, sendo 1590 delas dedicadas aos conteúdos e estágios profissionalizantes (os quais não poderiam ser desenvolvidos em menos de 600 horas). E o curso de auxiliar de enfermagem foi denominado de habilitação parcial, integralizado em 2200 horas, sendo 1110 horas profissionalizantes, das quais 400 dedicadas ao estágio supervisionado (GALVÃO, 1994).

A década de 70 se caracterizou pelo agravamento das condições de vida e de saúde da população brasileira. O Estado, visando diminuir a insatisfação da população e dos profissionais da área da saúde, fez um rearranjo nesta área e promulgou, em 1975, a Lei do Sistema Nacional de Saúde. As reformas administrativas adotadas favoreceram a produção dos serviços de saúde, sobretudo nas áreas industrializadas e urbanizadas do Brasil (SPRICIGO \& GELBECK, 1987).

O final desta década coincidiu com o esgotamento do modelo médico-assistencial privatista, $o$ qual apresentava: custos crescentes; prática médica dominante baseada nos aspectos curativo-reabilitadores; incapacidade de alterar os perfis de morbi-mortalidade; crescente insatisfação dos usuários, prestadores de serviços e trabalhadores da saúde e a perda gradativa da qualidade dos serviços prestados, direta ou indiretamente, pela Previdência Social. Neste contexto, têm início uma proposta de atenção primária à saúde, ainda com uma visão reducionista e caracterizada pelo desenvolvimento de programas de medicina simplificada ou de estratégias de sobrevivência de grupos de risco (MENDES, 1994).

A conformação da Reforma Sanitária e a hegemonia do projeto, neo-liberal caracterizaram as políticas de saúde dos anos 80 , em um contexto de profunda crise econômica e em meio ao processo de redemocratização do país. A Reforma Sanitária veio apresentar três aspectos fundamentais nesta área: um conceito abrangente de saúde; a saúde como direito de cidadania e dever do Estado; e, a reformulação do Sistema Único de Saúde, caracterizado pela universalidade, integralidade de ações e descentralização. A VIII Conferência Nacional de Saúde, realizada em Brasília, em 1986, constituiu-se um momento importante para a conformação política-ideológica do setor (MENDES, 1994).

Neste período, $80 \%$ dos profissionais de enfermagem trabalhavam na rede hospitalar, quando teve início um processo de questionamento da prática profissional. Até então, estes profissionais desempenhavam passivamente seu papel de executores das políticas de saúde vigentes, reflexo de sua formação. Como conseqüência destas reflexões e tendo em vista que a Lei $\mathrm{n}^{0} 2.604 / 55$ já não mais satisfazia às necessidades sentidas pela categoria, o Conselho Federal de Enfermagem encaminhou aos órgãos competentes o projeto da nova lei do exercício profissional, a qual só foi promulgada, com muitos vetos, em 1986 (SPRICIGO \& GELBECK, 1987).

Nas décadas de 70 e 80 ocorreu aumento do número de escolas de enfermagem de nível superior e médio. Em 1983, existiam no Brasil, 81 cursos de graduação em enfermagem, 115 cursos de técnico de enfermagem e 145 cursos de auxiliares (ABEn, 1985).

Segundo levantamento feito pela ABEn/COFEN (ABEn, 1985), no Brasil, em 1983, dos técnicos de enfermagem, 74,1\% havia completado o curso regular de técnico de enfermagem e $24,3 \%$ tinha sido submetido à exame de suplência. Posteriormente, o exame de suplência para os profissionais de nível técnico foi suspenso, pelo Conselho Federal de Educação, a pedido do COFEN, alegando-se o grau de risco do paciente e o grau de complexidade de suas atribuições. Quanto aos auxiliares, $78 \%$ tinha concluído o curso regular e 15,9\% fez o exame de suplência. Sendo que existia 43.000 atendentes, trabalhando na área da saúde, sem preparo formal para esta atuação. Outro agravante é que, $65,5 \%$ do total de atendentes de enfermagem não recebia ou recebia raramente treinamento em serviço (ABEn, 1985).

A nova Lei $n^{\circ} 7498 / 86$ dispôs sobre o exercício profissional da enfermagem estipulando que a mesma passaria a ser exercida privativamente pelo enfermeiro, pelo técnico e auxiliar de enfermagem, e pela parteira, respeitando-se os respectivos graus de habilitação (ABEn, 1987). Determinou, ainda, a exclusão do atendente do quadro da enfermagem, o que, segundo SPRICIGO \& GELBECK (1987), foi um caminho para a profissionalização dos mesmos. No ano seguinte, o Decreto Lei ${ }^{\circ} 94406 / 87$ veio regulamentar a referida lei (ABEn, 1987).

Foi estabelecido como competência do técnico de enfermagem as atividades que envolviam orientação e acompanhamento do trabalho de enfermagem em grau auxiliar, e participação da assistência de enfermagem. Para o auxiliar, a lei determinou que o profissional deveria exercer atividades de nível médio, de natureza repetitiva, envolvendo serviços auxiliares de enfermagem sob supervisão, bem como a participação nas atividades de 
execução simples, no processo de tratamento. As atividades destes dois profissionais poderiam somente ser desempenhadas sob a orientação e supervisão do enfermeiro, o que mais uma vez não refletiu a situação real de assistência à saúde (ABEn, 1987).

Ao compararmos a nova lei do exercício com a anterior de 1955, observamos que o auxiliar de enfermagem teve suas competências restritas, de acordo com o seu nível de preparo profissional, sendo que, anteriormente, todas as atividades, exceto as de ensino e chefia, podiam ser por ele executadas. O técnico de enfermagem teve atribuições com um grau de complexidade maior que o auxiliar, porém, também ficou subordinado à supervisão do enfermeiro.

$\mathrm{O}$ artigo 23, da Lei do exercício profissional, estabeleceu que "o pessoal que se encontra executando tarefas de enfermagem, em virtude de carência de recursos humanos de nível médio nessa área, sem possuir formação específica regulada em Lei, será autorizado, pelo conselho Federal de Enfermagem, a exercer atividades elementares de enfermagem...", as quais teriam a orientação e supervisão do enfermeiro. Estabeleceu que tal autorização seria concedida durante o prazo de dez anos. Tal exigência se confrontou com as condições sócio-culturais destes trabalhadores e com os interesses dos seus empregadores, principalmente nos serviços privados de saúde (ABEn, 1987).

Como reflexo desta situação, através da Lei $\mathrm{n}^{\circ}$ 8.967/94, o presidente da república, estabeleceu que o parágrafo único do artigo 23 passaria a vigorar com a seguinte redação: "É assegurado aos atendentes de enfermagem, admitidos antes da vigência desta Lei, o exercício das atividades elementares de enfermagem..." (COREN - SP, 1997).

Diante desta nova determinação, os Conselhos Federal e Regionais de Enfermagem, em 1995, apresentaram duas resoluções para regulamentar a nova situação; a Resolução COFEN - 185, que dispôs sobre a autorização para a execução de tarefas elementares de enfermagem pelo pessoal sem formação específica, com prazo de validade de 12 a 36 meses, passível de renovação; e a Resolução COFEN - 186, que dispôs sobre a definição e especificação das atividades elementares de enfermagem a serem por eles executadas (RIBEIRO et al., 1996).
$\mathrm{Na}$ área educacional tivemos, recentemente, a promulgação da Nova Lei de Diretrizes e Bases da Educação Nacional, a Lei no 9394/96 (BRASIL, 1996), que ainda está sendo analisada pelas escolas, as quais necessitam de tempo para se adequarem às novas diretrizes.

O Decreto-Lei $\mathrm{n}^{\circ}$ 2.208/97 regulamentou a nova lei no que se refere ao ensino de nível médio e ensino profissionalizante. Observa-se um avanço neste decreto quando coloca que deverão ser realizados estudos de identificação do perfil de competências necessárias à atividade requerida, em cada um dos níveis profissionais, ouvindo os setores interessados, inclusive trabalhadores e empregadores. Esta regulamentação trouxe a oportunidade do trabalhador brasileiro aprender a exercitar a sua cidadania, se fazendo presente nos momentos em que ocorram as discussões referentes à determinação destes perfis de competências.

\section{CONSIDERAÇÕES FINAIS}

Na história da enfermagem brasileira, a legislação que norteia a formação e o exercício dos profissionais de nível médio, e por que não dizer a do próprio enfermeiro, muitas vezes veio regulamentar uma situação já consolidada na realidade de saúde do nosso país. Outras vezes, alguns atos legais tiveram como objetivo estabelecer uma situação mais favorável a uma prática profissional qualificada. Porém, apesar da legislação norteadora, são inúmeros os fatores sócio-políticoeconômicos que determinam a nossa atual situação profissional, a qual não pode ser compreendida dissociada do contexto da saúde brasileira, como um todo. É preciso continuar a discutir e refletir sobre nossa prática profissional ampliando nossa análise, a fim de compreender as transformações ocorridas e propor mudanças necessárias para uma prática de enfermagem mais qualificada.

A síntese trazida neste estudo, dos atos legais referentes ao ensino médio e ao exercício dos profissionais por ele qualificado, poderá auxiliar à compreensão desta temática e servir como fonte de consulta para os interessados nesta abordagem.

\section{TEACHING AT THE SECONDARY LEVEL AND PROFESSIONAL PRACTICE IN THE CONTEXT OF BRAZILIAN NURSING}

The formation of nursing professionals has been a concern through nursing history in our country. Within the context of development of nursing history, authors analysed the evolution of the legislation about the formation of nursing professionals at the secondary level as well as the legislation about their practice. 

ENFERMERÍA BRASILEÑA

La formación del profesional del área de enfermería ha sido motivo de preocupación en la historia de la enfermería moderna en nuestro país. En ese contexto histórico en que la enfermería brasileña se desarrolló, las autoras analizaron la evolución de la legislación sobre la formación de profesionales a nivel medio y las leyes que regulan la práctica de estos trabajadores.

TÉRMINOS CLAVES: enseñanza de enfermería, legislación de enfermería

\section{REFERÊNCIAS BIBLIOGRÁFICAS}

01. AlCÂNTARA, G. Princípios fundamentais do currículo. In: SEMINÁRIO REGIONAL DE ENFERMAGEM, 1, Curitiba, 1966. Relatório Final. Curitiba: ABEn, 1966. p.10-21.

02. ALMEIDA, M.C.P.; ROCHA, J.S.Y. O saber de enfermagem e sua dimensão prática. São Paulo: Cortez, 1986. 128p.

03. ASSOCIAÇÃO BRASILEIRA DE ENFERMAGEM. Levantamento dos recursos humanos e necessidades de enfermagem no Brasil. 19561958.Brasilia: ABEn, 1980.

04. ASSOCIAÇÃO BRASILEIRA DE ENFERMAGEM. Força de trabalho em enfermagem. O exercício da Enfermagem nas instituições de saúde do Brasil 1982/1983. Brasília: ABEn/COFEn, 1985. v. 1, p.1-236.

05. ASSOCIAÇÃO BRASILEIRA DE ENFERMAGEM. A "nova"lei do exercício profissional da enfermagem. Brasília: ABEn, 1987. (Caderno de Legislação/Documentos).

06. BAPTISTA, S.S.; BARREIRA, I.A. A luta da enfermagem por um espaço na universidade. Rio de Janeiro: URFJ, 1997. 193 p.

07. BRANDT, M.J.C.G.C.; MAGALHÃES, Z.R. Composição da força de trabalho versus formação de pessoal de enfermagem no Brasil: reflexos na prática. Belo Horizonte, 1992. p. 22. (mimeografado).

08. BRASIL. Ministério da Saúde/Fundação e Serviço de Saúde Pública. Enfermagem. Legislação e assuntos correlatos. 3. ed. Rio de Janeiro: Artes Gráficas da FSESP, 1974a. v.1, p. 1 - 209.

09. BRASIL. Ministério da Saúde/Fundação e Serviço de Saúde Pública. Enfermagem. Legislação e assuntos correlatos. 3. ed. Rio de Janeiro: Artes Gráficas da FSESP, 1974b. v.2, p.217 - 544.

10. BRASIL. Ministério da Saúde/Fundação e Serviço de Saúde Pública. Enfermagem. Legislação e assuntos correlatos. 3. ed. Rio de Janeiro: Artes Gráficas da FSESP, 1974c. v.3, p.545 - 763.
11. BRASIL. Lei 9394 de 20 de dezembro de 1996. Dispõe sobre as Diretrizes e Bases da Educação Nacional. Diário Oficial da União, Brasília, 23/ 12/96. Seção 1, p. 27834-41.

12. CARVALHO, A.C. Subsídios para a discussão sobre as atribuições do técnico de enfermagem. In: SEMINÁRIO REGIONAL DE ENSINO MÉDIO DE ENFERMAGEM, 1, Curitiba, 1966. Relatório Final. Curitiba: ABEn, 1966. p.30-40.

13. CARVAlho, A. Associação Brasileira de Enfermagem 1962-1976. Documentário. Brasília: ABEn, 1976. 541p.

14. CHRISTÓFARO, M.A.C. Sobre a profissionalização de trabalhadores da saúde sem qualificação específica. Rev.Bras.Enfermagem, v.47, n.1, p.1-8, 1994.

15. CONSELHO REGIONAL DE ENFERMAGEM SÃO PAULO. Principais legislações para o exercício da enfermagem. São Paulo, 1997.55p.

16. GALVÃO, E.A. Habilitações de nível médio na área da saúde, necessárias à operacionalização do Sistema Único. In: ASSOCIAÇÃO BRASILEIRA DE ENFERMAGEM. A profissionalização dos trabalhadores de nível médio que atuam nos serviços de saúde. Oficina de Trabalho. Relatório Final. Rio de Janeiro, 1994. 44p.

17. MENDES, E.V. (coord.) Distrito sanitário: o processo social de mudança das práticas sanitárias do Sistema Único de Saúde. 2. ed. São Paulo: HUCITEC-ABRASCO, 1994.

18. OLIVEIRA, M.I.R. de. Enfermagem e estrutura social. In: CONGRESSO BRASILEIRO DE ENFERMAGEM, 31, Fortaleza, Agosto de 1979. Anais. Brasília: ABEn, 1979. p.9-26.

19. RIBEIRO,G.S.; COSTA, S.F.G.da; LOPES, M.E.L. Legislação de Enfermagem: um guia para o profissional e estudante de enfermagem. João Pessoa: Almeida Gráfica e Editora, 1996. 155p. 
20. SECAF, V. A licenciatura em enfermagem e a prática de ensino: uma revisão crítica de sua evolução na Universidade de São Paulo. São Paulo, 1987. 188p. Tese (Doutorado) - Escola de Enfermagem, Universidade de São Paulo.

21. SEMINÁRIO REGIONAL DE ENSINO MÉDIO DE ENFERMAGEM, 1, Curitiba, 1966. Relatório Final. Curitiba: ABEn, 1966. 66p.
22. SPRICIGO, J.S.; GELBECK, F.L. Principais marcos da história da saúde e da enfermagem no Brasil e a evolução da legislação em enfermagem. In: ASSOCIAÇÃO BRASILEIRA DE ENFERMAGEM. A "nova” lei do exercício profissional da enfermagem. Brasília, 1987. (Cadernos de Legislação/Documentos). 